0-114 VALIDATION OF THE NEONATAL PAIN, AGITATION AND SEDATION SCALE FOR THE ASSESSMENT OF SEDATION IN NEONATAL INTENSIVE CARE PATIENTS

${ }^{1} \mathrm{~V}$ Giordano, ${ }^{1} \mathrm{P}$ Deindl, ${ }^{1} \mathrm{~S}$ Kuttner, ${ }^{2} \mathrm{~T}$ Waldhör, ${ }^{1} \mathrm{~T}$ Werther, ${ }^{1} \mathrm{C} C \mathrm{Czaba},{ }^{1} \mathrm{~A}$ Berger, ${ }^{1} \mathrm{~A}$ Pollak, ${ }^{1} \mathrm{M}$ Weninger, ${ }^{1} \mathrm{M}$ Oliscahr. 'Department of Pediatrics and Adolescent Medicine. Division of Neonatology Pediatric Intensive Care and Neuropediatrics, Medical University of Vienna, Vienna, Austria; ${ }^{2}$ Department of Epidemiology Center for Public Health, Medical University of Vienna, Vienna, Austria

\subsection{6/archdischild-2014-307384.181}

Background Implementation of sedation protocols based on regular sedation assessment using item-based scales can improve sedative treatment in children. There is a lack of validated tools to assess sedation in neonates.

Objective To validate the Neonatal Pain, Agitation and Sedation Scale (N-PASS) for the assessment of sedation in preterm and term neonates.

Methods The Nurse Interpretation of Sedation Score (NISS) was used to validate the N-PASS with regard to neonatal sedation. Paired assessments of both the N-PASS and the NISS were performed in 50 sedated neonates from 23 to 44 weeks' postmenstrual age.

Results A total set of 503 paired observations were included into analysis. The median N-PASS scores were significantly different for the three NISS categories (over-sedation (-8), adequate sedation (-2), under-sedation (0); $\mathrm{p}<.0001)$. Inter-observer agreement for the N-PASS sedation subscale was excellent (linearly weighted Cohen's Kappa:. 93), as was the internal consistency estimated by a Cronbach's alpha of 0.88 , which increased to.90 when the vital sign item was excluded from the N-PASS. There was no risk of under-sedation in patients with an N-PASS score $<-5$ and no risk of over-sedation with an N-PASS score $>$ 2. The N-PASS reliably detected over-sedation. Detection of under-sedation was markedly improved by simultaneous assessment of N-PASS pain scores which were significantly different in patients being considered adequately sedated vs. inadequately sedated (median N-PASS pain subscale score: 2 vs. 5 ).

Conclusion The N-PASS meets the requirements of a valid clinical tool to assess sedation in neonates and may facilitate the use of sedation algorithms in the neonatal intensive care unit.

\section{0-115 RELATIONSHIP BETWEEN ADVERSE DRUG REACTIONS AND OFF-LABEL/UNLICENSED DRUG USE IN HOSPITALISED NEONATES. REMINEO STUDY}

${ }^{1} \mathrm{KA}$ Nguyen, ${ }^{2} \mathrm{~N}$ Paret, ${ }^{1} \mathrm{~F}$ Plaisant, ${ }^{3} \mathrm{C}$ Giraud, ${ }^{1} \mathrm{~A}$ Beissel, ${ }^{2} \mathrm{~A}$ Millaret, ${ }^{1} \mathrm{~F}$ Al-Sohim, ${ }^{3} \mathrm{~S}$ Gaillard, ${ }^{2} \mathrm{~T}$ Vial, ${ }^{1} \mathrm{O}$ Claris, ${ }^{3} \mathrm{~B}$ Kassai. ${ }^{1}$ Neonatal Intensive Care Unit and Neonatology, Hospices Civils de Lyon/Hôpital Femme Mère Enfant/Lyon 1 University, Lyon, France; ${ }^{2}$ Pharmacovigilance Center of Lyon, Hospices Civils de Lyon/Lyon 1 University, Lyon, France; ${ }^{3}$ Clinical Pharmacology, Hospices Civils de Lyon/EPICIME/CIC 1407/Hôpital Femme Mère Enfant/UMR 5558/CNRS/Lyon 1 University, Lyon, France

10.1136/archdischild-2014-307384.182

Background and aim Data regarding the association between the off-label drug use and adverse drug reactions (ADRs) in neonates is scarce. The main aims of this study are to evaluate prospectively the relationship between adverse drug reactions and offlabel or unlicensed (OLUL) drugs in 2 neonatal centres in Lyon (France), and to provide more information on prescribing practice, the amplitude, nature and consequences of OLUL drug use. Methods The French summaries of product characteristics in Theriaque 2012 (a prescription products guide) are being used as a primary reference source for determining drug labelling.
Detection of ADRs is carried out by health care professionals and research groups using a trigger tool and patients' electronic health records. The causality between suspected ADRs and drug is evaluated using the WHO and the French methods of imputability.

Preliminary results for a 12 month period 910 neonates were included. $671(73,7 \%)$ were preterm. 94,8\% (CI 95: 93,3-96,3) of children received at least one OLUL drug, $66 \%$ of 8891 prescriptions were used in OLUL manner. $80 \%$ of the 96 validated ADRs were classified as severe. $84 \%$ of drugs related to ADRs were used in OLUL manner.

Conclusion Our study confirmed that OLUL drug utilisation is common in neonates. This study will bring more evidence on the correlation between OLUL drug use and ADRs. Institutions and pharmaceutical industry should develop clinical trials for neonates, and ensure they do not remain a "therapeutic orphan". A specific reference source for drug used in neonates would be helpful.

\section{0-116 PREMATURE INFANT PAIN PROFILE (PIPP) IN NEONATAL INTENSIVE CARE UNIT: A PILOT STUDY}

L Peipoch, S Breinig, S Pelluau, L Berthomieu, M Gineste, MC Bloom, M Marcoux. Réanimation Néonatale et Pédiatrique, Chu Toulouse, Toulouse, France

\subsection{6/archdischild-2014-307384.183}

Background and aims Premature Infant Pain Profile (PIPP) has been studied and validated in intensive care units but seldom in neonates with ventilatory support. The aim of the study was to assess PIPP (feasibility, inter-rater reproductibility, easiness) while endotracheal suctionning in ventilated newborns in order to use it later for pain treatment monitoring.

Methods Prospective study done in a level III neonatal intensive care unit, from 2013 march 5th to 2013 April 25th. 25 newborns with invasive mechanically ventilatory support were involved and they were filmed during the procedure. Four observators noted individually PIPPscale for each baby: the patient's nurse and a department's resident in the room and, an NIDCAP experienced paediatrician and the resident making the study, after viewing the video. The inter-rater agreement was assessed by the Cohen's Kappa coefficient.

Results $100 \%$ of the PIPP scales were done. The global interrater agreement was poor, with a kappa coefficient at 0,303 $(0,035-0,571)$ and especially for the mimic items. $33 \%$ of the nurses found the PIPP scale difficult to use. Mean PIPP during endotracheal suctionning varied from 8.7 to 9.3.

Conclusions Pain assessment by PIPP scale was poorly reproducible and hard to nurse's use in the ventilated newborns. Neonatal pain and sedation protocol guided by PIPP scale seems us to be difficult to implement in intubated neonates.

\section{Sepsis/Infections}

\section{0-117 COMPARISON OF SUPERIOR VENA CAVAL OXYGEN SATURATION (SCVO2) AND FEMORAL VENOUS OXYGEN SATURATION (SFVO2) IN CHILDREN WITH SEPTIC SHOCK}

J Sankar, A Shukla, A Jain, N Dubey. Pediatrics, PGIMER Dr RML Hospital, New Delhi, India

10.1136/archdischild-2014-307384.184 


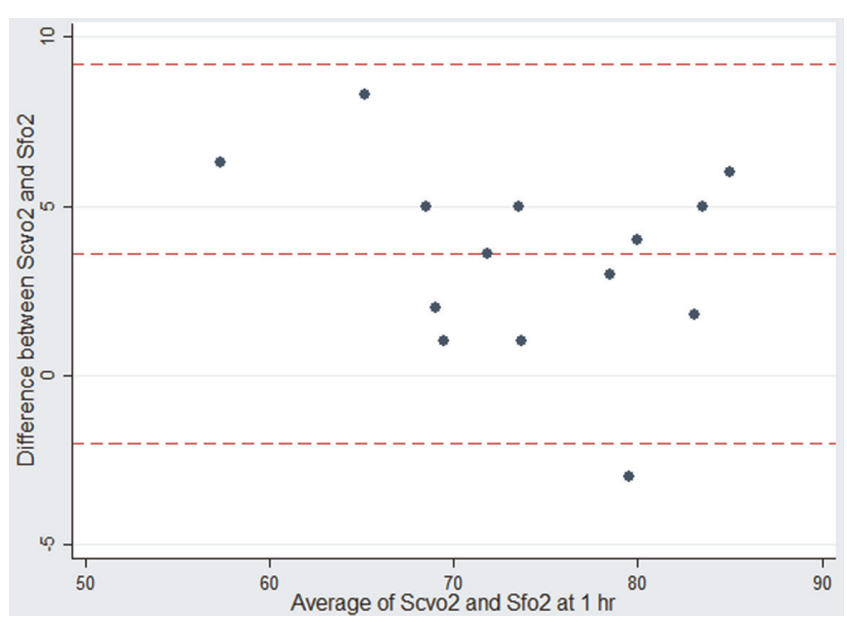

Abstract 0-117 Figure 1 Agreement between $\mathrm{ScvO}_{2}$ and $\mathrm{SfvO}_{2}$ values at $1 \mathrm{~h}$

Background and aim Femoral vein catheterization is very commonly performed while managing children with septic shock. However, the agreement between superior venal caval $\left(\mathrm{ScvO}_{2}\right)$ and femoral venous oxygen saturation $\left(\mathrm{SfvO}_{2}\right)$ has not been reported in children till date. Our aim was to evaluate the agreement between $\mathrm{ScvO}_{2}$ and $\mathrm{SfvO}_{2}$ values.

Methods Children with septic shock in whom femoral vein catheter was inserted before shifting to the ICU were eligible. Paired blood samples from subclavian/Internal jugular vein and femoral catheters were drawn simultaneously after initial fluid resuscitation in these children and analysed. Agreement was assessed by Bland and Altman (BA) analysis. The study was approved by IRB.

Results A total of 32 patients were enrolled. The mean $\mathrm{ScvO}_{2}$ and $\mathrm{SfvO}_{2}$ were $72.3 \%$ and $76 \%$ respectively ( $\mathrm{p}<0.001$ ). BA analysis showed relatively poor agreement between $\mathrm{ScvO}_{2}$ and $\mathrm{SfvO}_{2}$ with mean bias of 3.6 and $95 \%$ limits of agreement of 1.95 to $9.25(\mathrm{r}=-0.28, \mathrm{p}=0.14)$ (Figure 1$)$. In general, $\mathrm{SfvO}_{2}$ values were higher than $\mathrm{ScvO}_{2}$ values with 14 of the 32 children having values $\geq 5 \%$. The $\mathrm{SfvO}_{2}$ had poor sensitivity (45.5\%) but $100 \%$ specificity for detecting low saturations. The PPV was $100 \%$ and the NPV was $77.8 \%$. As SfvO2 values were generally higher than $\mathrm{ScvO}_{2}$ values, we tried a higher cut-off for $\mathrm{SfvO}_{2}$ to detect low mixed venous saturations. With a $\mathrm{SfvO}_{2}$ cut off of $72 \%$, the sensitivity and specificity were both $100 \%$.

Conclusions A higher cut off of $72 \%$ for $\mathrm{SfvO}_{2}$ may be used in place of $\mathrm{ScvO}_{2}$ in situations where $\mathrm{ScvO}_{2}$ estimation has failed or is impractical. Our study findings however, need further validation.

\section{0-118 HIGH PREVALENCE OF CYTOMEGALOVIRUS PROTEINS IN SURGICAL SPECIMENS OBTAINED FROM INFANTS WITH NECROTIZING ENTEROCOLITIS, BOWEL PERFORATION OR BOWEL STRICTURE}

${ }^{1} \mathrm{~S}$ Omarsdottir, ${ }^{2} \mathrm{M}$ Agnarsdottir, ${ }^{3} \mathrm{~A}$ Orrego, ${ }^{1} \mathrm{E}$ Skantz, ${ }^{4} \mathrm{M}$ Vanpée, ${ }^{1} \mathrm{~A}$ ${ }^{1} \mathrm{C}$ Söderberg-Nauclér. 'Department of Medicine Solna, Karolinska Institute, Stockholm, Sweden; ${ }^{2}$ Institute of Immunology Genetics and Pathology, Uppsala University, Uppsala, Sweden; ${ }^{3}$ Department of Clinical Pathology and Cytology, Karolinska University Hospital, Stockholm, Sweden; ${ }^{4}$ Department of Women's and Children's Health, Karolinska Institute, Stockholm, Sweden

10.1136/archdischild-2014-307384.185
Background and aims Necrotizing enterocolitis (NEC) is a frequent cause of neonatal surgical emergency. The pathogenesis of the disease is incompletely understood. Postnatal cytomegalovirus (CMV) infection can present clinically as NEC and be related to bowel perforation or intestinal stricture in the neonate. The aim of this study was to evaluate the presence of CMV infection in intestinal samples obtained from infants with these conditions. Methods Surgical specimens from infants diagnosed with NEC, bowel perforation or intestinal stricture during year 1997-2009 were collected from the pathology departments at Karolinska University Hospital and Uppsala University Hospital. The intestinal samples were retrospectively analysed for CMV Immediate Early Antigen (CMV-IEA) and CMV Late Antigen (CMV-LA) by immunohistochemistry.

Results Sixty-six intestinal specimens from 47 preterm infants and 10 full term infants were collected. The median gestational age of the infants was 27.9 weeks and their median birth weight was 1015 grams. The pathological diagnoses were NEC ( $\mathrm{n}=$ 36), NEC and intestinal perforation $(n=12)$, intestinal perforation $(n=12)$, sequel after NEC $(n=3)$ and unspecific changes $(\mathrm{n}=3)$. CMV-IEA and CMV-LA was detected in $85 \%$ and $61 \%$ of the intestinal tissue samples, respectively. Of these samples, $71 \%$ and $38 \%$ were classified as having a high-grade $(\geq 25 \%)$ CMV infection.

Conclusions CMV proteins were detected in the vast majority of intestinal specimens obtained from infants diagnosed with NEC, bowel perforation or intestinal stricture. These findings support a possible role of CMV in the pathophysiology of NEC and other surgical conditions in the neonate.

\section{Teaching Using Simulation}

\section{0-119 CAPNOGRAPHY IMPROVES NEONATAL FACE MASK VENTILATION}

G Hawkes, M Kenosi, CA Ryan, EM Dempsey. Department of Paediatrics and Child Health, University College Cork, Cork, Ireland

\subsection{6/archdischild-2014-307384.186}

Background Assessment of effective positive pressure ventilation (PPV) in neonatal mask ventilation can be difficult.

Objectives To determine which was the most effective method of providing PPV: a T-piece resuscitator (TPR) with no device attached (ND), a TPR containing an in line $\mathrm{CO}_{2}$ detector (NeoStatCO $\left.\mathrm{C}_{2}<\mathrm{Kg}^{\circledR}\right)(\mathrm{COD})$ or a TPR with a capnography device attached (CAP).

Methods This was a randomised crossover trial. Neonatal trainees were randomly assigned to each method (ND, COD or CAP). They then alternated methods such that all participants provided PPV with each method for a period of $2 \mathrm{~min}$ on a $\mathrm{CO}_{2}$ producing mannequin. Participants were video recorded to determine the amount of effective ventilations delivered, and the overall percentage efficacy of each method. Informed consent was obtained.

Results 23 paediatric trainees provided a total of 6035 ventilations and $91.1 \%$ were deemed to be effective. There was no statistically significant difference between the percentage efficacy of breaths delivered between the three methods. Percentage of effective ventilations with ND, COD and CAP were $90.8 \%$, $90.9 \%$ and $91.8 \%$ respectively. $15(65 \%)$ of the trainees indicated a preference for the COD method and 8 (35\%) for the CAP method. No trainees indicated a preference for the ND 